\title{
On Interaction between Times Changes and National Inheritance of National Traditional Sports Culture
}

\author{
Xiaomao Tan \\ Department of Physical Education of Jining University, Qufu, 273155, China
}

Key words: National tradition sports culture, Times change, National inheritance, Interaction

\begin{abstract}
Traditional sports culture, a unique cultural phenomenon of human society formed from the wild and offensive nature through rational way of competition like labor, game and education, in the process of transformation of themselves when their animal instinct changed into conscious activity. Traditional sports culture, as the precondition and power of national traditional sports culture and cultural development, not only has distinct times changes; but also is diverse, national and inheritable, as the origin and foundation of the development of national traditional sports culture. Therefore, we believe that it is of positive historical significance and practical significance to conduct research and analysis from the perspective of interactions between the times changes and national heritage of national traditional sports culture.
\end{abstract}

\section{Introduction}

National traditional sports culture is the origin of China's current sports culture, which developed on the basis of traditional sports culture, so it is inheritable. The development of sports culture since ancient times, after a course of several times, has made it changeable. The interaction between the times changes and national inheritance has practical significance in the process of social civilization.

\section{Times Changes of National Traditional Sports Culture}

\section{Connotation of Times Changes of National Traditional Sports Culture}

Human society developed with the change of time, so did the culture of human society. and the movement of culture is a part of culture. Culture's motive change is that in the process of culture change, the national traditional culture that belongs to culture will also change with time, so it is times changeable.

There are two aspects of changing. The first is the change of sports events, and the other is that of sports culture. As communication between China and other countries are increasingly close, other countries' competitive sports culture is casting a strong impact on China's traditional sports culture. The cultural changes caused by foreign cultures usually has three kinds of results, the first one is to perish, which means that the national traditional sports culture will be eliminated under the strong impact of foreign cultures, such as playing sticks of the Miao People and the wooden bench dragon of the Tujia People; the second one is to fusion, which means that foreign sports culture and the traditional culture integrate with each other, creating a new type of sports activities, such as competitive martial arts and free combat; the third one is to digestion, which means that, on the basis of adhering to the traditional sports culture of our country, the essence of the foreign culture is digested, so that it is gradually integrated into the traditional culture of our country, such as weight lifting, shooting and rafting ${ }^{[1]}$.

\section{Analysis on Times Changes of National Traditional Sports Culture}

The national traditional sports culture changes with the social changes. It is a positive change in the course of the change. It shows that the change of the traditional sports culture has the characteristics of the times, and it is the symbol of cultural progress. After the change, the sports culture not only increases the characteristics of traditional culture, but also embodies the modernization of traditional culture. Throughout the changes of traditional sports culture, it can be found that it is a trend of progress, and its cultural system, material system and spiritual civilization have achieved a coordinated development. In different periods of development, the times have 
different influences on the traditional sports culture. In modern society, economic development is dominant, which leads to a lot of material cultural heritage and intangible cultural heritage to be gradually abandoned, and many cultural characteristics of sports culture disappear.

\section{National Inheritance of National Traditional Sports Culture}

\section{Connotation of National Inheritance of National Traditional Sports Culture}

Culture is not static, but gradually changing with time going by, accumulated and inherited. These two changes is the basic law of traditional sports culture. Cultural progress and development is the combination of the two. Traditional sports culture, in the process of continuous inheritance, is changing in accordance with this law. The inheritance is mainly reflected in the national heritage. Different countries has different national characteristics. Unique national character is the inner motive for national sustainable development and the basic mechanism of the inheritance of traditional culture $^{[2]}$.

\section{Analysis of National Inheritance of National Traditional Sports Culture}

In the process of continuous development, the national traditional sports culture inherited the national character. In this paper, national inheritance of national traditional sports culture are deeply analyzed, and the specific contents are as follows. First, the inheritance of social ideology. In people's daily life, the social ideology is the main carrier which dominates the external forces and reflects the people's minds. Sports culture and religion culture are created by human beings. Having the same creator, they are inter-penetrating and indivisible with each other. In the religious activities, it contains the contents of the traditional sports culture, in the traditional sports activities, also retained part of the ritual and religious celebration; second, the inheritance of social and cultural life. Social and cultural life contains national customs and festivals. From the social and cultural life, the original side of a national traditional sports culture can be seen. During the inheritance, generations of people have increasingly heavy responsibility to bear, not only to inherit the nation's unique cultural signs handed down from generation to generation, but also the unique cultural concepts ${ }^{[3]}$; third, Inheritance of production and life style. National traditional sports culture and material production methods have an inseparable connections. The cultural heritage can not be separated from the material production mode, and the traditional culture can compensate the material production. Therefore, Cultural inheritance is a kind of material culture phenomenon, which is created and inherited in the specific ecological environment, and always in the production practice.

In today's society, the widely circulated sports are formed on the basis of national traditional culture. They are subject to the influence of regional culture in the formation process. The Olympic movement has expanded its range gradually to become a global campaign. In such a situation, sport culture of western countries is slowly becoming the mainstream. Sports culture in other countries is keeping up with it, setting it as the developing goal. With the rapid development of Western sports culture, national traditional sports culture in other countries is facing severe challenges. How to inherit and carry forward the traditional sports culture has become the urgent problem.

\section{Necessity and Practical Significance of Interaction between Times Changes and National Inheritance of National Traditional Sports Culture}

\section{Necessity of Times Changes and National Inheritance in Development of National Traditional Sports Culture}

First, The times change and national inheritance of the national traditional sports culture is an essential part of the development of the society and culture, which is the prerequisite for the development of culture. Human culture is continuously developing, changing and being inherited. Social development will cause some contradictions in the traditional culture. These contradictions will intensify the contradictions between new and old factors, so that they will depart or integrate with each other. They will undergo the process of mutation, elimination and renewal, and eventually transit from the old balance to a new, thus changing the traditional sports culture; in the process of development, traditional culture not only will produce internal contradictions, but also be impacted 
by the foreign cultures. At this time, the traditional sports culture will absorb the essence of foreign culture, change the original cultural structure, and realize the new coordination and unity. This process is the interaction between social cultural change and inheritance. In the interactive relationship, the national culture of the national traditional sports culture will be preserved and inherited for a long-term, and the culture of current social characters will be absorbed by the national traditional sports culture, which makes the social culture diverse ${ }^{[4]}$.

Second, times changing and national inheritance is the motive of national traditional culture development. National traditional sports culture is an important part of human social culture, and has a significant impact on social and cultural development. China is a big country, which contains many ethnic groups. They have unique cultural characteristics, and serious conflicts in exchanges. Each regime change created a platform for further fusion of the national traditional sports culture. For example, the Yuan Dynasty was established by the minority. When ethnic minorities was in power, carry on the reform would be carried out to the Central Plains culture for the fusion of culture. Both cultures developed in the process of conflict and fusion, and national traditional sports culture also obviously changed.

\section{Practical Significance of Times Changes and National Inheritance of National Traditional Sports Culture}

The society is developing constantly, so is the national traditional sports culture. The change and inheritance of the traditional sports culture not only has a positive effect on cultural development, but also has practical significance to social development. In this paper, the practical significance is to be deeply analyzed, and the specific contents are as follows:

Firstly, improving people's national sports culture consciousness. In the process of continuous development, minority nationality gradually formed the national sports culture under the influence of production labor and life and religion belief. In the past, the ethnic discrimination and national oppression made the relationships among ethnic groups not harmonious, with serious barriers. In such a background, sports activities were generally for celebration and worship, and the national sports culture had not been formed. After 1949, the relationships among ethnic groups gradually have been eased, communication has become more frequent, sports culture has gradually changed from a single form, and its content has been becoming more rich. In such a situation, people's national sports culture consciousness gradually rises.

Secondly, identification of national sports culture connotation. National traditional sports culture is an important part of the traditional culture, as it has been recognized by people, this culture can not fade. National traditional sports culture is produced in a specific historical stage, so it can be changed gradually with the social changes. Therefore, in the process of developing national traditional sports culture, we should take the traditional culture as the center, and then integrate the real culture into it, so that it can form the culture that reflects the social reality and the comprehensive spirit. Then people's aesthetic taste and entertainment needs can be met, and the further development of national sports culture in the cultural level can be promoted.

Thirdly, reshaping the image of national sports culture. In the process of continuous development of national traditional sports culture, there inevitably will be coexistence of the essence and dross. Facing such a situation, we should renew the idea, break through the old customs in the process change and inheritance, and shape new image of national sports culture. For the long-term development of national traditional sports culture, we should discard the dross of content and absorb the essence of the times. Only in this way can we form national traditional sports culture that promotes the social development. For instance, China's martial arts, go, dragon boat racing and other sports have been innovated, and now national dragon boat race, go and martial arts competitions have been formed [5].

Fourthly, strengthening national unity. National traditional sports have rich cultural connotation and special forms, with a strong national style, attractive and simple. With these characteristics, national traditional sports culture plays more important in Chinese socialist spiritual civilization construction. After 1949, the relationship between the various ethnic groups has been eased to a certain degree, but there is still a gap. In order to eliminate these barriers, the government has taken 
many measures, such as organizing the central leadership visit to the ethnic regions. These activities have gradually eliminated the barriers between peoples, to achieve the purpose of national unity, mutual assistance and common development.

\section{Conclusion}

In the current trend of globalization, the national sports cultures are continuously communicating and integrating with foreign sports culture. Traditional sports culture is growing up in the constantly process of renewing. The continuous development of the sports culture since ancient times makes it changeable, which is the precondition and power of national traditional sports cultural development. Only through this kind of change, the essence of the culture being inherited, can the national traditional sports culture develops in social culture. We must correctly understand the importance of national traditional sports, and that making our own efforts and contributions to the protection and inheritance of national traditional sports culture is not only of profound historical significance, but also of positive practice significance.

\section{Acknowledgments}

Topic: Research on Evolution and Inheritance of Traditional Sports Culture in Shandong, the hometown of Confucius and Mencius. NO.: 15JSGX053.

\section{References}

[1] Lu Weifen, Xing Zhijie. The inheritance and Transcendence of National Traditional Sports Culture in The Context of Cultural Identity. Sports and Science, 2012, 33 (3): 71-74.

[2] Song Zhengyuan. On Development of National Traditional Sports Culture from The Cultural Perspective. Journal of Chengdu Sport University, 2012, 38(5): 60-61, 68.

[3] Wang Nan. On Mass Media and Reconstruction and Development of Chinese Traditional Sports Culture. News Knowledge, 2013(10): 36-37,45.

[4] Liu Weilong, Long Peilin. Present situation and Countermeasures of Excellent National Traditional Sports Culture Transmission in World Chinese Education. Journal of Wuhan Institute of P. E, 2014, 48(12): 55-58.

[5] Liang Tian, Zhang Yuchao. On Subject of Right of National Traditional Sports Culture in China, and Its content. Sports, 2015(5): 150-152,27. 